\title{
articles
}

\section{Epidemiology of drug abuse treatment in South Africa}

\author{
Shandir Ramlagan, MDevSt \\ Human Sciences Research Council, Pretoria \\ Karl Peltzer, PhD \\ Human Sciences Research Council, Pretoria, and \\ Department of Psychology, University of the Free State, \\ Bloemfontein
}

Gladys Matseke, BA (Hons)

Human Sciences Research Council, Pretoria

Background. The aim of the study was to explore the epidemiology of drug abuse treatment in South Africa.

Methods. Treatment demand statistics were analysed from South African National Council on Alcoholism and Drug Dependence and the South African Community Epidemiology Network on Drug Use records, and a rapid situation assessment was conducted. Twenty-one key informant interviews were conducted in all 9 provinces among provincial substance abuse co-ordinators, and one manager per treatment centre from a sample of treatment centres. Three focus groups were conducted and 46 self-administered questionnaires were distributed among inpatients at 2 selected treatment centres in Free State and North West provinces. Qualitative data were analysed using grounded theory, and quantitative data analysed using SPSS.

Results. Treatment records show that the most frequent substance of abuse was alcohol (51\%), followed by cannabis (21\%), crack/cocaine (9.6\%), heroin/opiates (7.9\%), methamphetamine (Tik) $(4.5 \%)$, prescription/over-thecounter drugs (2.0\%), and cannabis/mandrax (1.7\%). More substance abusers were male, of lower education, white or black, than were female, more highly educated, coloured and Indian/Asian. Key informant interviews showed that females are the 'hidden' substance abusers and tend not to be identified in research statistics and at treatment centres. Poverty, unemployment, lack of recreational facilities, being surrounded by substance abusers, and long work shifts were also mentioned as factors contributing to substance abuse. The age of initiation of substance abuse using non-drugs such as glue was 9 years old, alcohol 10 - 12 years old, dagga 11 .
12 years old, poly-drug use (alcohol, tobacco and dagga) 14 years old, and harder drugs such as cocaine and heroin at 16 - 17 years old, as reported by key informants. Family care and support, improved socio-economic conditions and increased law enforcement would help to discourage substance abuse.

Conclusion. Prevention interventions and policies in South Africa should focus on reducing substance abuse by targeting the 'at risk populations' identified in this study.

Empirical evidence collected in the late 1990s pointed to a gradual increase in drug-related problems and substance abuse in South Africa. The challenges associated with substance abuse continue to be perpetuated by socio-economic and developmental factors' and because South Africa is one of the world's largest producers of some drugs such as cannabis, most of which is consumed regionally, with shipments going to the Netherlands and the UK. ${ }^{2}$ Both locally and at a global level, moreover, drug consumption and trafficking is very active. ${ }^{3}$

In South Africa, alcohol and drug abuse was highlighted by former President Nelson Mandela in his opening address to Parliament in 1994, ${ }^{4}$ as a problem among the social pathologies that needed attention. Since 1994, there has been a dramatic increase in the establishment of private treatment services (both licensed and unlicensed). 5,6 An initiative to develop norms and standards for in-patient treatment centres has recently been completed.' Steps have also been taken to institute protocols for managing the detoxification of patients at secondary hospitals in several provinces. ${ }^{8}$

An international example of substance abuse patterns is in Texas, USA, where alcohol was found to be the primary drug of abuse in terms of dependence, death, treatment admissions and arrests, while cocaine was found to be the primary illicit drug for which Texans commenced treatment. ${ }^{9}$ In 2003 , cocaine /crack and powder) represented $27 \%$ of all adult admissions to the Texan Commission on Alcohol \& Drug Abuse-funded treatment programmes. Abusers of crack cocaine made up $19 \%$, and of powder cocaine $8 \%$, of all admissions. ${ }^{9}$

In Nigeria, 367 substance abuse clients were admitted to a university's teaching hospital's cross-sectional study between 1980 and $1984 . .^{10}$ Those between the ages of 15 and 30 tended to abuse cannabis and amphetamine more than alcohol, whereas 
those $\geq 31$ years old tended to abuse alcohol. ${ }^{10}$ A Maldives rapid situation assessment ${ }^{11}$ found among 204 drug users that $97 \%$ were male, with a mean age of 21.4 years. Almost half of these respondents $(47 \%)$ were $<20$ years old. Primary drugs used in the previous month in the Maldives were opioids (76\%), cannabinoids (12\%) and alcohol (9\%). Most of the key informants and focus group participants attributed their reasons for drug use to family problems, experimentation, peer pressure, lack of awareness, psychological problems, easy availability, lack of educational and employment opportunities, boredom and stress. ${ }^{11}$

In Cameroon, 454 respondents participated in a rapidassessment, snowball-sampled study. ${ }^{12}$ The ages of drug abusers ranged from 11 to 60 (mean 29), of whom 15\% were <20 years old and $10 \%$ were $>40$ years old; $83 \%$ of the drug abusers were male, $46 \%$ of respondents had been introduced to drugs by friends, most shared their drugs, 13\% had tried drugs out of curiosity, 11\% wanted to enhance their work or academic performance, $11 \%$ were influenced by peer pressure, and $9 \%$ had been given drugs to sell. Of the respondents, $86 \%$ currently used cannabis, $6 \%$ used amphetamines, and $3 \%$ used cocaine. ${ }^{12}$ The study also reported that alcohol consumption was common among drug users.

Wansi et al. ${ }^{12}$ also showed that the reasons given by respondents in Cameroon for drug consumption could be categorised into three groups: psycho-social, economic, and therapeutic/ medical. Respondents stated that an inefficient legal system, the involvement of some law enforcement officers in drug trafficking, the relationship between drug abuse and criminality, heightened political awareness of the 1990s, and economic crises contributed to increased drug abuse. ${ }^{12}$

The above literature clearly shows that substance abuse is prevalent around the world. Of all illegal substances, cannabis is most widely used. Abusers start using illegal substances as early as 11 years old, and the majority are male. These facts are critical to understanding the epidemiology of substance abuse in any country and therefore will assist in programme planning. The aim of our study was to investigate the epidemiology of drug abuse treatment in South Africa.

\section{Methods}

\section{Study design}

Client treatment and treatment demand statistics were compiled from the South African National Council on Alcoholism and Drug Dependence (SANCA) and the South African Community
Epidemiology Network on Drug Use (SACENDU) records. Specialised treatment facilities are defined as those delivering one or more specialised substance abuse treatment services to people with alcohol and other drug (AOD) problems. ${ }^{14}$ A variety of treatment facilities are covered by this definition, including detoxification, rehabilitation and psychological treatment. Using this definition, sole providers of services (e.g. a psychologist) or facilities that provide substance abuse services in conjunction with other health services (e.g. general hospitals) are not included in the sample. In addition, self-help groups and services that only provide information, education, or crisis intervention are not classified as specialist $A O D$ treatment facilities.

Secondly, a rapid situation assessment was conducted whereby 3 data sets were collected: namely, key informant (KI) interviews, focus groups (FGs) and in-patient self-administered questionnaires. The 3 data collection methods were useful for data triangulation (to verify information and cross-check conclusions).

\section{Study population}

Key informants: A total of $21 \mathrm{Kls}$ agreed to be interviewed. Kls consisted of 9 provincial substance abuse co-ordinators, of whom there was one per province, and one manager per treatment centre, who were all informed about the study. Three experienced HSRC master's degree researchers, who received training in quantitative and qualitative data collection methods and a booster session prior to fieldwork, conducted a total of 21 telephonic interviews with Kls between 22 February and 2 March 2007. Of these, $5 \mathrm{Kl}$ interviews were conducted in Free State Province (FS), 3 each in Limpopo (LP) and Eastern Cape (EC), 2 in KwaZulu-Natal (KZN), 4 in North-West (NW), and 1 each in Mpumalanga (MP), Western Cape (WC), Northern Cape (NC) and Gauteng (GP). Each interview took 25 - 45 minutes. Prior to each interview, informed consent was obtained from the interviewee.

Focus group participants: $A$ total of 3 male FGs were conducted at 2 conveniently selected treatment centres in FS and NW provinces, where one currently finds limited data. The FG sample only included male respondents because of the limited number of female patients at the treatment centres, and female clients refusing to participate in the FG sessions. Each participant signed informed consent documents prior to their involvement. Participants who declined to participate were thanked for their time and not included in the session. The session was used to gather data on drug users, nature of drug use, types of drugs available, prices of drugs, packaging and distribution mechanisms, and usage patterns. All FGs were conducted in English. 
Self-administered questionnaire respondents: All admitted in-patients ( $\geq 18$ years old) at the 2 above-mentioned treatment centres were requested to fill in a questionnaire. The study was introduced to the in-patients at the treatment centres, and written consent was obtained from participants. Respondent who were comfortable with the questionnaire contents proceeded to complete it under supervision of an HSRC co-ordinator. Patients who had problems with the questionnaire language were assisted by a co-ordinator in their chosen language.

\section{Measurements}

An interview schedule was compiled and used for $\mathrm{Kl}$ interviews. Sections of the interview schedule included biographical information, nature of drug use in the province, types of drugs available, prices of drugs, packaging and distribution mechanisms, and usage patterns. An FG guide was compiled and used to gather in-depth data from the FG sessions. The sections were the same as those in the self-administered questionnaires. An in-patient self-administered questionnaire was designed and used to record in-patients responses. The sections of the questionnaire were the same as in the interview schedules.

\section{Data analysis}

Regarding the qualitative analysis, all interviews from FGs and $\mathrm{Kls}$ were transcribed from audiotapes. Transcripts were cleaned and proofed prior to analysis. Concepts derived from grounded theory ${ }^{13}$ were used to guide qualitative analysis to identify themes and concepts. Two researchers, including an expert in qualitative research methods, evaluated the study transcripts. There was a $25 \%$ overlap in transcript evaluations to allow reliability checks in theme and content identification. Kappa coefficients were used to tabulate missed themes and concepts across analysis.

For quantitative analysis, all data gathered from in-patient selfadministered questionnaires were analysed using SPSS version 14.0. Qualitative data from open-ended questions were coded for SPSS. Once entered, the data were cleaned and cross-checked to ensure suitability for analysis. The data set was evaluated, and corresponding frequencies and cross-tabulations were done. Data were crosstabulated with demographic information, and means were also calculated where applicable.

\section{Ethics approval}

The study was approved by the HSRC Research Ethics Committee. Permission was obtained from the National Department of Social Development, which then facilitated approval from its provincial departments, leading to approval by the managers of the treatment centres.

\section{Results}

Results are divided and are presented in 3 sections: (i) drug abuse treatment centre statistics, (ii) $\mathrm{Kl}$ perceptions on substance abuse, and (iii) in-patient treatment centre survey and perceptions.

\section{Drug abuse treatment centre statistics}

The primary substance of abuse in 2007 (from July to December) according to most treatment centres ( $N=75)$ in South Africa as provided by data from SACENDU (in-/out-patients = 8 935), was alcohol $(51 \%)$, followed by cannabis $(21 \%)$, crack/cocaine (9.6\%), heroin/opiates $(7.9 \%)$, methamphetamine (tik) $(4.5 \%)$, prescription/OTC drugs (2.0\%) and cannabis/mandrax (1.7\%) (Table I).

According to the SACENDU Research Brief, ${ }^{15}$ alcohol is still the most common primary substance of abuse among patients seen at specialist treatment centres across all sites (except the Western Cape (WC)I, accounting for 52\% of admissions in GP, 50\% of admissions in $\mathrm{KZN}, 44 \%$ of admissions in $\mathrm{MP}$, and $62 \%$ of admissions in the Central Region (FS, NC and NW). The mean age of patients whose primary substance of abuse was alcohol ranged from 36 to 41 years across all sites. Among patients younger than 20 years in most sites, the most common substance of abuse was cannabis, except in the WC where it was methamphetamine.

Treatment admissions were concentrated in 5 of the 9 provinces of South Africa: GP (34.2\%), WC (34.2\%), KZN (10.7\%), EC (6.8\%) and MP (6.2\%) (Table I). Treatment demand was overrepresented for men (83.1\%), Whites (41.6\%) and Black Africans (32.2\%) as opposed to Coloureds (23.4\%) and Indian/Asians $(2.8 \%)$. A steady increase has been noted in treatment demand for young people (below 20 or 22 years respectively) to now $22.3 \%$ of total treatment demand (Table I).

Based on the SANCA national treatment centres (centres: $N=31$, clients: $N=8$ 518,2005/2006), the 3 major referral sources were (i) self, (ii) family/friends, and (iii) employer/workplace. The level of education of the participants was lower than Grade 8 in 10.5\%, Grade $8-10$ in 36.6\%, Grade $11-12$ in $40.5 \%$, and tertiary education in $12.5 \%$. Thirty-nine per cent were employed full-time, $26 \%$ were unemployed, and 25\% were students. Most participants (58\%) had never married (were single), 25\% were married, $4 \%$ were cohabiting, $8 \%$ were divorced, and 


\begin{tabular}{|c|c|c|c|c|c|c|c|c|c|c|}
\hline In/out-patients & EC & $\mathrm{KZN}$ & WC & GP & MP & $\mathrm{LP}$ & FS & NC & NW & Total \\
\hline Number & 608 & 954 & 3058 & 3053 & 556 & 49 & 354 & 172 & 131 & 8935 \\
\hline Male (\%) & 81 & 90 & 76 & 80 & 88 & 80 & 84 & 81 & 88 & 83.1 \\
\hline Black (\%) & 35 & 25 & 7 & 34 & 60 & 31 & 39 & 23 & 36 & 32.2 \\
\hline Coloured (\%) & 32.5 & 7 & 70 & 11 & 4 & 0 & 14 & 66 & 6 & 23.4 \\
\hline Indian/Asian (\%) & 2.5 & 14 & $<1$ & 3 & 1 & 2 & 1 & 1 & 1 & 2.8 \\
\hline$<20$ & & 51 & 26 & 20 & 20 & $14^{*}$ & 11 & 30 & 9 & 22.3 \\
\hline$*<22(\%)$ & 20 & & & & & & & & & \\
\hline $20-34$ & & 24 & 46 & 42 & 45 & $49^{*}$ & 35 & 40 & 44 & 41.5 \\
\hline *22 - $35(\%)$ & 48.5 & & & & & & & & & \\
\hline $35-49$ & & 20 & 20 & 28 & 28 & $31^{*}$ & 40 & 26 & 33 & 28.3 \\
\hline$* 36-59(\%)$ & 28.5 & & & & & & & & & \\
\hline \multicolumn{11}{|l|}{$* 50+(\%)$} \\
\hline$* * 60+(\%)$ & 7.5 & & & & & & & & & \\
\hline $65+(\%)$ & $<1$ & - & $<1$ & $<1$ & 0 & - & 1 & 1 & 2 & 0.4 \\
\hline Alcohol (\%) & 45 & 39 & 30 & 47 & 42 & 61 & 67 & 65 & 63 & 51.0 \\
\hline Cannabis (\%) & 18 & 17 & 13 & 19 & 40 & 14 & 17 & 27 & 24 & 21.0 \\
\hline Cannabis/mandrax (\%) & 8.5 & $<1$ & 3 & 2 & 0 & - & 1 & 1 & - & 1.7 \\
\hline Crack/cocaine (\%) & 20 & 9 & 4 & 14 & 7 & 16 & 10 & 1 & 5 & 9.6 \\
\hline Heroin/opiates (\%) & 4 & 32 & 13 & 10 & 7 & 2 & 1 & 2 & - & 7.9 \\
\hline Prescription/OTC (\%) & 2 & 2 & 1 & 4 & 2 & - & 2 & - & 5 & 2.0 \\
\hline Methamphetamine (\%) & 2.5 & - & 36 & $<1$ & $<1$ & - & - & 2 & - & 4.5 \\
\hline $\begin{array}{l}\text { Source: Adapted from SACENDU } \\
*^{* *}=\text { age groups for which data }\end{array}$ & & & & & & & & & & \\
\hline
\end{tabular}

$4 \%$ widowed. ${ }^{17}$ Based on SACENDU reports from 1998 to 2008, the overall number of treatment admissions significantly increased over the past 10 years. ${ }^{15,16}$ Percentage of admissions for cannabis, heroin and methamphetamine increased between 1996 and 2005, while the admission percentages decreased for alcohol. ${ }^{16}$ There was an increase in demand for drug treatment by young persons, especially related to cannabis and methamphetamine. 18,19

\section{KI perceptions on substance abuse}

Four over-arching broad themes were identified: demographics of users, consumption patterns, drug market patterns, and treatment. User demographics were further broken down into drug abuse patterns by gender, perceived age of initiation, and education levels of the substance abuser. Sub-themes under consumption patterns include the extent of the problem in the area, perceived prevalence and consumption patterns of methamphetamine and injecting drug use; and causes, location and mode of use. Drug marketing patterns sub-theme consisted of pricing and quantity levels, types and quality levels of illicit drugs, as well as how and where drugs were purchased.

\section{Drug abuse patterns by gender}

More males than females present with drug abuse problems to treatment facilities. All participants believed that the male:female substance abuser ratio was about 3:1. Respondents generally believed that males have more funding and opportunity to utilise or abuse substances. It also appears that parents are stricter with female than with male children, and that it is more socially acceptable for male youths to smoke and consume alcohol. The quotes from the interviews give a view of $\mathrm{Kl}$ perceptions regarding drug abuse patterns by gender.

'Males have more time to themselves than females.'

'... it is more socially acceptable for younger males to smoke and drink.'

'Young males present with more substance problems. It is easier for them to get into it. It has something to do with the way young men are socialised. Parents are stricter with girls than they are with boys. As a result, boys always have more time to experiment.'

The reported percentages were from the observations at treatment centres and could be misleading because substance prevalence 
for females could be much higher but were underestimated, as females are not seen in rehabilitation centres, according to this $\mathrm{Kl}$ :

'Females/housewives are substance abusers, especially alcohol and over-the-counter medication but they use it at home and do not get caught - their substance abuse prevalence could be very high; it is just that they do not come to the (rehab) center.'

\section{Perceived reasons for substance abuse}

Poverty, unemployment, lack of recreational facilities, being surrounded by substance abusers, long shifts at work, high stress as a result of a combination of unemployment and family problems, boredom and work pressures were also mentioned as factors contributing to substance abuse.

FG participants and questionnaire respondents mentioned their reasons for using illicit drugs as 'experimenting' (48\%), 'psychological problems (excessive worrying, anxiety, sadness, sexual dysfunctions)' (36\%), 'peer pressure' (32\%), 'family problems' (25\%), 'easy availability' (23\%), 'lack of awareness' (14\%) and 'lack of recreational activities' (9\%).

\section{Perceived age of initiation}

Respondents pointed out that, although most users of illicit drugs tend to start in their teens, some users start earlier. The age of initiation for glue was reported as 9 years old, alcohol $10-12$ years old, dagga 11 - 12 years old, poly-drug use lalcohol, tobacco and dagga) 14 years old, and harder drugs such as cocaine and heroine at 16 - 17 years old. According to some $\mathrm{Kls}$, softer drugs such as alcohol and tobacco are used at a younger age as these drugs are easily accessible at home. Harder drugs are used at an older age because these drugs are more expensive and users/abusers have more money available to them at an older age. It appears that as youth get older, they have more funds available to them, and they therefore start using more expensive substances. An issue of concern here is that younger children have access to softer drugs at home.

\section{Education level of drug abusers}

A high prevalence of substance users is reported by Kls to exist at high schools. Some Kls, however, were unable to give a specific education bracket or stated that education did not influence substance abuse but that higher substance abuse prevalence is generally seen in lower- to middle-income households.

\section{Consumption patterns}

The three foremost substances reported to be used were tobacco, followed by alcohol and then cannabis.

\section{Perceived prevalence and consumption patterns of methamphetamine}

Most Kls stated that meth (tik) consumption is slowly increasing. The exception was the Western Cape where there is a higher prevalence of meth. In the other provinces, the statement that tik was slowly increasing was made with caution as each treatment centre interviewed had 1 - 3 patients in the previous year. These patients were in most cases not original residents of the province but had come from the Western Cape.

Although used by all groups, tik is mainly used by male youth. Tik seems to be cheaper than cocaine and heroin, as reported by Kls and, as it is a new drug, more people want to experiment with it. As cases of tik usage are low, Kls were unable to state if current treatment facilities were able to cope, but they did state that there are either no or few in-patient treatment facilities. The fees for treatment at facilities were stated to be unaffordable to most users. Communities (apart from that of the Western Cape) were also unaware of the drug, owing to its low usage prevalence. More awareness is needed, as well as in-patient treatment facilities.

\section{Injecting drug use}

Cases of parenteral drug use were reported in $L P, K Z N, E C$, FS, WC, NC, NW and MP. Although one GP respondent did not report on this question, other research shows that GP has a prevalence of parenteral drug use. Interestingly, such cases are stated to be rare or not common. Some Kls stated that heroin is mainly injected, while others stated that at times it is like a fashion trend which comes and goes depending on what people are saying on the streets, as is evident in these quotes:

'Those who take heroin, inject - this is not something that is new as it has been going on for many years.

'It is at times fashionable to inject so people do that, but then someone hears something, then it all stops and then after some time it starts again. It depends on what people want and believe - if you believe that inhaling gives you a faster buzz, then you do that.'

'Yes, but it is a last resort if everything else fails to get them high fast enough.' 
Of concern is needle sharing. Most Kls reported that needle sharing occurs minimally and mainly between people who know each other. In a country with an extremely high HIV prevalence, this is unacceptable. Needle sharing by the youth, as one KI said, was even more unacceptable and frightening as youth do not have enough money to purchase heroine/crack/rocks, and therefore they share money to buy one 'hit' of the drug:

'...the youth, as they do not have a lot of money so they put money together and buy one and then share the needle to use."

\section{Extent of the problem}

All participants in all provinces believed that the substance abuse problem was currently very serious and the problem escalating, as said in these quotes:

'... serious problem as since 1997 as there have been a gradual increase in the number of young people admitted.'

'... very serious as compared to five years ago as there are more people in hospital now and the amount of dagga psychosis is increasing every year.'

'massive increase in substance abuse in the last 5 years'

\section{Location and mode of substance abuse}

Kls reported that alcohol was mainly consumed alone yet social drinkers consume it in pubs, taverns, at home and in public places. Taking drugs, however, is seen as a more social activity at mainly parties, clubs, public places etc.

Overwhelmingly, the most common mode of drug use cited by Kls was smoking, followed by drinking (swallowing). Respondents stated that tobacco, cannabis, mandrax, nyaope, heroin and tik are smoked.

\section{Drug market patterns}

\section{Prices and quantity levels of illicit drugs}

According to most Kls, either the prices of drugs seem to have come down or buyers (especially the youth) have more money available.

\section{Types and quality levels of illicit drugs}

Cases of patients abusing substances such as glue, nail polish, benzene, petrol, methylated spirits, Tippex and even a mix of Coca-Cola and Disprin have been mentioned. Nyaope la mix of cannabis and heroine) and so-called sugars (a drug made up of cocaine, heroine and rat poison) are also mentioned as being prevalent.

Most Kls stated that drug quality seems to have decreased as drugs are mixed with inferior substances /leading to more negative reactions by clients) or the manufacturing process leads to more negative reactions - as stated in the quotes:

[Regarding cannabis] '... growers are now using hydroponics and therefore we are seeing higher THC levels. This leads to more co-morbid disorders like psychosis. With this new technology now, there is this change."

'... there are more people in hospital now and the amount of dagga psychosis is increasing every year.'

'Drug quality is now poorer as users complain about it and state that before they used to take 3 - 4 rocks to get a high and now they take 15 to get the same high.'

\section{Treatment}

Drop-out rates of patients at facilities depend on the type of facility (in- or outpatient), facility location (e.g. big city or small town) and the substance abused. Some facilities stated a drop-out rate of 2 - $8 \%$ while others stated $40 \%$ and higher. Generally, higher dropout rates were seen at outpatient-based facilities, as abusers have a higher chance of being influenced before they complete the treatment. Kls stated that relapse rates could be $50 \%$ for cannabis, $33 \%$ for alcohol and $65 \%$ for harder drugs such as cocaine and heroin. One main reason stated for the high relapse rates was the nature of care in terms of outpatient rather than inpatient care.As outpatients, the facility has little control over their patients.

Motivation also plays a big role in patient drop-out or relapse, as was mentioned by most Kls. Lack of funds to continue after-care services and the lack of after-care facilities were also given as reasons for relapse. Those who work also have to return to work and therefore drop out of treatment facilities.

One $\mathrm{KI}$ mentioned that in $\mathrm{KZN}$ there is a high (40\%) drop-out rate for patients seeking rehabilitation for sugars. The reason stated is that sugars patients take a medication called Subutex to decrease cravings and suppress withdrawal symptoms. When they relapse, they expect to get Subutex from the treatment facility, without the counselling. The facilities do not use Subutex substitution and therefore patients drop out. Subutex (buprenorphine hydrochloride) and Suboxone (buprenorphine hydrochloride and naloxone hydrochloride) are approved for the treatment of opiate 
dependence by preventing symptoms of withdrawal in heroin and other opiates. ${ }^{23}$

\section{In-patient treatment centre survey and perceptions}

Reported below are the results from both FG interviews and structured questionnaires from treatment centre clients. The data are combined in this section to provide more details and properly represent substance usage. The final sample for the selfadministered questionnaire included 46 in-patients (25 refused) from 2 treatment centres. Eighty-seven per cent of the sample was male, and 13\% female, with a mean age of 35.3 ISD 9.7 and range 18 - 54 years. Most (85\%) in-patients had completed secondary school education, 54\% were employed full-ime, 22\% unemployed, 13\% self-employed full-time, $7 \%$ worked in the informal sector (including housewives and home-makers), 1 (2\%) was a student, and 1 was self-employed part-time.

\section{Reasons for admission}

As an ice-breaking question, FG participants were asked why they were at the treatment centre. This question was designed to start the process of participants talking. As expected, FG respondents were at the centre because they either had alcohol or illicit drug abuse problems. Some respondents depended on both alcohol and drugs, as can be seen in the quote below, and were at the centre to receive help in breaking their dependency.

'I'm here because I was too much depended on alcohol and drug abuse, dependence is one of the reasons I am in this treatment centre.'

'I am not addicted to alcohol, [I'm] addicted to the feeling that the alcohol brings. But mostly it's in your brain, it's in your mind but we don't have the ability to deal with it, the knowledge to do something about it. The only thing that is there is that I want to, I want to.

\section{Licit drug use}

Four out of 5 treatment centre clients $(N=46)$ smoked daily and were hazardous or harmful drinkers; $39 \%$ smoked 20 or more cigarettes per day; and 50\% were probably alcohol dependent ( $\geq 20$ score on the AUDIT).

Treatment centre clients usually drank in their own homes (65\%), in licensed premises (e.g. pubs, clubs) (17\%), at someone else's house $(11 \%)$, raves/dance parties $(4 \%)$, and in public places (e.g. parks) (2\%).

\section{Illicit drug use}

One out of 3 treatment centre clients had used cannabis, opiates and/or sedatives almost daily prior to treatment, and 15\% used cocaine/crack almost daily prior to treatment (Table III. Onset of first use of illicit drugs was 15 years for sedatives, 16 years for cannabis, 17 years for opiates, 18 years for cocaine, 21 years for amphetamine-type stimulants, and 22 years for hallucinogens.

FG participants mentioned either alcohol or cannabis as their substances of first use (quote below):

'I started when I was 12 years old with dagga and I was 16 when I used mandrax, from 34 years I smoke crack. In my experience, crack made me feel better and mandrax calmed me down.'

'I started with dagga and alcohol.'

\section{Primary drug use}

The primary drug was alcohol, followed by tobacco, cannabis, cocaine/crack, opiates and sedatives (Table III). Secondary drugs were alcohol, cocaine/crack and cannabis, while tertiary drugs

Table II. Frequency and onset of illicit drug use prior to admission

\begin{tabular}{|c|c|c|c|c|}
\hline Non-medical use only & $\begin{array}{c}\text { Past month } \\
\text { (\%) }\end{array}$ & $\begin{array}{c}\text { Weekly } \\
\text { (\%) }\end{array}$ & $\begin{array}{c}\text { Almost } \\
\text { daily } \\
(\%)\end{array}$ & $\begin{array}{c}\text { Onset } \\
\text { (Mean yrs) }\end{array}$ \\
\hline Cannabis (dagga, marijuana, pot, grass, hash etc.) & 54 & 17 & 30 & 16.0 \\
\hline Cocaine (coke, rocks, crack etc.) & 37 & 15 & 15 & 17.5 \\
\hline Amphetamine-type stimulants (speed, ecstasy, tik, cat etc.) & 19 & 12 & 0 & 20.9 \\
\hline Inhalants (nitrates, glue, petrol, paint thinners etc.) & 4 & 0 & 0 & 18.6 \\
\hline Sedatives or sleeping pills (valium, mandrax, serepax, rohypnol etc.) & 22 & 0 & 27 & 15.3 \\
\hline Hallucinogens (LSD, acid, mushrooms, PCP, Special K etc.) & 11 & 0 & 0 & 22.3 \\
\hline Opiates (heroin, morphine, methadone, codeine etc.) & 22 & 6 & 31 & 16.6 \\
\hline
\end{tabular}




\begin{tabular}{|c|c|c|c|}
\hline & Primary & Secondary & Tertiary \\
\hline Alcohol & 54 & 42 & 40 \\
\hline Tobacco & 16 & 6 & 10 \\
\hline Cannabis & 11 & 18 & 10 \\
\hline Cocaine/crack & 8 & 24 & 13 \\
\hline Amphetamine-type stimulants (speed, ecstasy, tik, cat etc.) & 0 & 3 & 0 \\
\hline Inhalants & 0 & 0 & 0 \\
\hline Sedatives or sleeping pills (valium, mandrax etc.) & 3 & 3 & 3 \\
\hline Hallucinogens (LSD, acid, mushrooms etc.) & 0 & 0 & 10 \\
\hline Opiates (heroin, morphine, methadone, codeine etc.) & 5 & 3 & 10 \\
\hline
\end{tabular}

were alcohol followed by cocaine/crack, tobacco, cannabis, hallucinogens and opiates.

The FGs showed that most respondents were introduced to a specific substance by peers who included their friends (43\%), family $(7 \%)$ or colleagues $(21 \%)$. A few respondents started abusing substances through their families. The venue of first illicit drug use was mostly at home (33\%) and in public places (e.g. parks) (30\%); see quotes:

II started when I was 16 years old. After school when parents are not at home. Otherwise over the weekend, you don't go to pubs or you might at the school party, but you don't drink at school, you drink before you go to school.'

'Morning before we go to school we will start at the house, it's the very old empty house, smoke 2 to 3 green pops, school start at 8 , we should be in class at 8 .'

The illicit drug supply was mostly through a friend or acquaintance $(53 \%)$, self-purchased from a retailer $(20 \%)$, parent $(6 \%)$, pub or bottle store $(3 \%)$, other source $(3 \%)$ and undetermined (16\%).

\section{Treatment services}

One out of 3 respondents (35\%) had been treated for drug problems prior to visiting the centre. The main drugs for previous treatment were alcohol (60\%), cannabis (11\%), opiates (1 1\%), tobacco (1 1\%), and cocaine/crack (7\%). The form of treatment was in-patient rehabilitation (57\%), self-help group (such as AA) $(20 \%)$, private doctor's office (15\%), and hospital in-patient $(10 \%)$.

As a closing question, FG participants were asked what would help them to stop or decrease their reliance on substances. Three main issues arose: family care and support, socio-economic conditions, and law enforcement.

\section{Discussion}

Our study found that most substance abusers were male, lower educated, white or black. There was a lower prevalence among females, higher educated, Coloured and Indian/Asian, although this could be explained by a hidden epidemic among the latter population. This possibility became evident in the qualitative interviews as it was reported that substance prevalence for females could be much higher but was underestimated because females were not seen in rehabilitation centres. It is probable therefore that females are hidden substance abusers and are lost in research statistics and to treatment centres. A low level of female substance abuse research respondents was also seen in the Maldives ${ }^{11}$ and Cameroon. ${ }^{12}$

The most commonly used substance of abuse in treatment centres in South Africa was alcohol, followed by cannabis, crack/ cocaine, heroin/opiates, methamphetamine (tik), prescription/ OTC drugs and cannabis/mandrax. There has been a substantial drop in demand for treatment for alcohol-related problems. ${ }^{20}$ For example, the proportion of patients in specialist substance abuse treatment centres in Cape Town who had alcohol as their primary substance of abuse decreased from $81 \%$ in the second half of 1996 to $39 \%$ in the second half of $2003 .^{21}$ This was mainly due to the closure of state treatment centres focusing on people with alcohol-related problems, and the increased demand for services by younger illicit drug users. ${ }^{22}$ The government's plan was to reduce tertiary care services while simultaneously increasing primary care services to patients with alcohol problems. This has generally not occurred, and services remain insufficient to meet demand, are poorly distributed geographically, and fragmented between health and social welfare sectors. ${ }^{20}$

Parry et al. ${ }^{24}$ found a significant increase in cocaine-related treatment admissions in South Africa and stated that poly-drug use was high, with cocaine often used with alcohol, cannabis 
and other drugs. Alcohol, cocaine, and opiate consumption were the top primary drugs of abuse in Texas, ${ }^{9}$ Nigeria, ${ }^{10}$ the Maldives ${ }^{11}$ and Cameroon. ${ }^{12}$ Alcohol consumption is prohibited in the Maldives and punishable under Shari'ah law, yet cases of alcohol consumption are documented. "'

Of concern in our study is that the number of treatment admissions increased significantly over the past 10 years and is similar to other findings including those of SANCA, ${ }^{18}$ SACENDU ${ }^{16}$ and Peltzer et al. ${ }^{25}$ An increase was noted in the percentages of admissions for cannabis, heroin and methamphetamine between 1996 and 2005, while the percentage of admissions for alcohol decreased. Plüddemann et al. ${ }^{19}$ reported that a dramatic increase in admissions for methamphetamine occurred between 2004 and 2006. An increase in drug treatment demand by young persons (especially related to cannabis and methamphetamine) was also noted in this study, as was seen in Nigeria. ${ }^{10}$ However, Peltzer et al. ${ }^{26}$ showed that, after 1994, our borders opened not only to democracy and economic activity but also to the importation of major illicit drugs.

With increasing treatment admissions over the past 10 years, our study also found that age of initiation of substance abuse such as glue was reported as 9 years old, alcohol 10 - 12 years old, dagga 11 - 12 years old, poly-drug use (alcohol, tobacco and dagga) at 14 years old, and harder drugs such as cocaine and heroin at $16-17$ years old. The qualitative interviews showed that there are concerns that younger youth have access to softer drugs at home and, as they have more money available to them, start abusing drugs earlier. Poverty, unemployment, lack of recreational facilities, being surrounded by substance abusers, and long shifts at work were also mentioned by Kls and substance users as factors contributing to substance abuse. These contributory factors were also present in the Maldives ${ }^{11}$ and Cameroon. ${ }^{12}$

We found higher drop-out rates at out-patient-based facilities compared with in-patient-based facilities, as abusers have a higher chance of being influenced before they complete the treatment. One out of 3 self-administered questionnaire respondents was treated for drug problems prior to visiting these centres.

\section{Conclusion and recommendations}

The above findings should be considered by the National Departments of Social Development and Social Welfare when planning to make treatment centres more suitable for all licit and illicit substance abusers in South Africa. The findings could also assist in planning prevention programmes to reduce substance abuse. Prevention interventions and policies should be aimed at reducing abuse levels by targeting the at-risk populations identified in this study. The WHO World Mental Health Survey found that unmet needs for mental health (including substance abuse) treatment are pervasive and especially concerning in lessdeveloped countries (including South Africa). ${ }^{26}$

We make the following recommendations:

- free access to treatment services for disadvantaged groups

- expand the number of treatment centres, especially into rural areas

- increase support groups

- more skilled staff are required, including occupational therapists, nurses, social workers and counsellors to help substance abusers in treatment centres

- surveillance for $\mathrm{HIV} /$ hepatitis B/C among drug users in treatment is required

- mobilise the community by educating them about substance abuse

- stricter law enforcement

- in-patient treatment facilities should be coupled with good aftercare facilities

- more infrastructure, such as buildings, is needed for current treatment centres to be able to expand.

We thank the South African National Department of Social Development for funding the study, all participants including treatment centres, and $\mathrm{Mr}$ Gorden Mohlala for data collection and contributing to the report from which this article was written.

\section{References}

1. Rocha-Silva L. Drug use within the context of other socioeconomic conditions in South Africa (unpublished research report). Pretoria: HSRC, 1997.

2. Peltzer K, Ramlagan S. Cannabis use trends in South Africa. South African Journal of Psychiatry 2007; 13(4): 126-131.

3. Drug Advisory Board. National Drug Master Plan. Pretoria: Department of Welfare and Population Development, 1999

4. Mandela N. Opening address to the South African Parliament. Pretoria: Office of the President, 1994

5. Department of Welfare. White Paper for Social Welfare. Principles, Guidelines, Recommendations, Proposed Policies and Programme for Developmental Social Welfare in South Africa. Pretoria: Department of Welfare, 1997.

6. National Department of Social Development. Treatment Centres. Pretoria: National Department of Social Development, 2003.

7. Muller L, Fisher S, Myers B, et al. Norms and Standards for Substance Dependence Inpatient Centres in South Africa. (A report submitted to the United Nations Office on Drugs and Crime.) Cape Town: Bridges, 2003.

8. Parry CDH. South Africa: alcohol today. Addiction 2005; 100: 426-429.

9. Maxwell JC. Substance Abuse Trends in Texas, June 2004. Austin, Texas: The Gulf Coast Addiction Technology Transfer Centre, 2004

10. Ahmed MH. Drug abuse as seen in the University Department of Psychiatry, Kaduna, Nigeria, in 1980-1984. Acta Psychiatr Scand 1986; 74(1): 98-101.

11. Narcotics Control Board. Rapid Situation Assessment of Drug Abuse in Maldives 2003. Republic of Maldives: Narcotics Control Board, 2003. 
12. Wansi E, Sam-Abbenyi A, Befedi-Mengwe R, et al. Rapid assessment of drug abuse in Cameroon. UNODC Bull 1996; 79-88.

13. Strauss \& Corbin. Basics of Qualitative Research: Grounded Theory Procedures and Techniques. London: Sage Publications, 1990

14. Torres MI, Mattick, RP, Chen R, Baillie A. Clients of Treatment Service Agencies: March 1995 Census Findings. Canberra: Australian Government Publishing Service, 1995

15. South African Community Epidemiology Network on Drug Use (SACENDU) Research Brief. Monitoring Alcohol \& Drug Abuse Trends in South Africa (July 1996-June 2007) 2007; 10(2): 1-14

16. South African Community Epidemiology Network on Drug Use (SACENDU). Monitoring Alcohol and Drug Abuse Treatment Admissions in South Africa. Phase 23, July to December 2007. Cape Town: SACENDU, 2008.

17. South African National Council on Alcoholism and Drug Dependence (SANCA). Treatment Profile of Clients in Counselling: Second Report April 2006 - March 2007. Johannesburg: SANCA, 2007

18. Plüddemann A, Myers B, Parry CDH. Surge in treatment admissions related to methamphetamine use in Cape Town, South Africa: implications for public health Drug Alcohol Rev 2008; 27: 185-189.

19. Parry $\mathrm{CDH}$. A review of policy-relevant strategies and interventions to address the burden of alcohol on individuals and society in South Africa. South African Psychiatry Review 2005; 8: 20-24.
20. Plüddemann A, Parry CDH, Bhana A, Harker N, Potgieter H, Gerber W. Monitoring alcohol and drug abuse trends in South Africa Uuly 1996-December 2003) SACENDU Research Brief 2004; 7: 1-8.

21. Parry $C D H$, Bhana A, Myers B, et al. Alcohol use in South Africa: Findings from the South African Community Epidemiology Network on Drug Use (SACENDU) project. J Stud Alcohol 2002; 63: 430-435.

22. U.S. Food and Drug Administration (USFDA). Center for Drug Evaluation and Research Subutex (buprenorphine hydrochloride) and Suboxone tablets (buprenorphine hydrochloride and naloxone hydrochloride) http://www.fda.gov/cder/drug/ infopage/subutex_suboxone/default.htm (accessed 20 July 2009).

23. Parry $C D H$, Plüddemann $A$, Myers $B$. Cocaine treatment admissions at three sentine sites in South Africa (1997-2006): findings and implications for policy, practice and research. Substance Abuse Treatment, Prevention and Policy 2007; 2: 37.

24. Peltzer K, Ramlagan S, Johnson BD, et al. A Review of Illicit Drug Use and Treatment in South Africa. Pretoria: Human Sciences Research Council, 2007.

25. Peltzer K, Ramlagan S, Johnson BD, Phaswana-Mafuya R. Illicit drug use and treatment in South Africa: a review. Substance Use Misuse (in print).

26. Wang PS, Aguilar-Gaxiola S, Alonso J, et al. Use of mental health services for anxiety, mood, and substance disorders in 17 countries in the WHO world mental health surveys. Lancet 2007; 370(9590): 841-850. 